\title{
ANÁLISE DA EFICIÊNCIA NA UTILIZAÇÃO DOS RECURSOS PÚBLICOS NOS ANOS INICIAIS DO ENSINO FUNDAMENTAL DOS MUNICÍPIOS DO SUDOESTE DO PARANÁ
}

\section{ANALYSIS OF EFFICIENCY IN THE USE OF PUBLIC RESOURCES IN THE INITIAL YEARS OF ELEMENTARY SCHOOL OF THE MUNICIPALITIES OF SOUTHWEST PARANÁ}

\author{
Manuele Ribeiro da Silva ${ }^{1}$ \\ Universidade Tecnológica Federal do \\ Paraná (UTFPR) \\ manuelersilvas@gmail.com \\ https://orcid.org/0000-0002-8346-2109
}

\author{
Sandra Mara Iesbik Valmorbida \\ Universidade Tecnológica Federal do \\ Paraná (UTFPR) \\ smiesbik@gmail.com \\ https://orcid.org/0000-0001-6607-7957
}

\begin{abstract}
RESUMO
A educação é um fator fundamental para o desenvolvimento social e econômico, cabendo ao Estado realizar a provisão e alocação dos recursos disponíveis de maneira adequada a fim de promover políticas públicas assertivas no setor. Com isso, a presente pesquisa teve como objetivo analisar a eficiência na utilização dos recursos públicos destinados aos anos iniciais do ensino fundamental nas escolas públicas de responsabilidade dos quarenta e dois (42) municípios da região Sudoeste do Paraná durante os anos de 2013, 2015, 2017 e 2019. Para isto, utilizou-se a metodologia Análise Envoltória de Dados (DEA) com o modelo BCC e orientação a output. Como insumos foram considerados: (i) recursos financeiros; (ii) matrículas; (iii) docentes; e, (iv) escolas, e como produto, a nota alcançada por cada um dos municípios do Índice de Desenvolvimento da Educação Básica (IDEB). Os resultados mostraram que nos quatro períodos analisados menos de $15 \%$ dos municípios alcançaram a eficiência 1,000, concluindo que a grande maioria dos municípios do Sudoeste do Paraná não aloca seus recursos de forma eficiente, apresentando possibilidades de melhoria.
\end{abstract}

Palavras-Chave: Eficiência. Recursos Públicos. Educação. DEA.

\section{ABSTRACT}

Education is a fundamental factor for social and economic development, it is up to the State to provide and appropriately allocate available resources in order to promote corrective public policies in the sector. Thereby, this research aimed to analyse the efficiency in the use of public resources destined to the early years of elementary school in public schools under the

\footnotetext{
${ }^{1}$ Via do Conhecimento, s/n - KM 01 - Fraron, Pato Branco - PR, 85503-390
} 
responsibility of the forty-two (42) municipalities in the Southwest region of Parana during the years 2013, 2015, 2017 and 2019. For this purpose, the Data Envelopment Analysis (DEA) methodology was used with BCC model and output orientation. As inputs were considered: (i) financial resources; (ii) enrollments; (iii) teachers; and (iv) schools, and as a product, the score achieved by each of the municipalities in the Basic Education Development Index (IDEB). Finally, the results showed that in the four analysed periods less than $15 \%$ of the analysed municipalities reached efficiency 1,000, concluding that the great majority of the municipalities in the Southwest of Parana do not allocate their resources efficiently, showing the possibility of improvements.

Keywords: Efficiency. Public Resources. Education. DEA.

\section{INTRODUÇÃO}

A educação é um fator fundamental para o desenvolvimento da sociedade. Ela configura-se como um elemento que aumenta a produtividade, a velocidade do crescimento econômico, diminuindo a pobreza (Besen, Scherer, Araújo, \& Serafim, 2017). De acordo com a Constituição da República Federativa do Brasil (1988), a educação é dever do Estado e um direito de todos.

A fim de garantir a ordem e o bem estar social, o Estado tem por finalidade empregar os recursos arrecadados na implementação de políticas públicas essenciais ao povo, e como meio para isso, desenvolve suas atividades financeiras com base no orçamento público (C. L. Oliveira \& Ferreira, 2017; Kohama, 2017).

Com o objetivo de alocar recursos limitados a fim de atender necessidades ilimitadas da população, o governo precisa buscar alocar os recursos arrecadados da maneira mais eficiente possível. Fazendo-se fundamental refletir acerca do modo mais adequado de investir os recursos disponíveis a fim de que a alocação dos mesmos se torne eficiente (Savian \& Bezerra, 2013; Besen et al., 2017; Monte \& Leopoldino, 2017).

O conceito de eficiência provém da combinação ótima de insumos e métodos, de maneira que gerem o máximo de produto dentro do processo produtivo. Analisar a eficiência da aplicação dos recursos no setor público é fundamental, uma vez que demonstra o desempenho da gestão dos administradores públicos e contribui diretamente para melhoria das decisões e dos resultados, visto que o reflexo dos recursos alocados nos diversos setores deve ser transformado em serviços de qualidade e colaborar para o crescimento dos indicadores sociais (Peña, 2008; F. J. V. Souza, Silva, \& Araujo, 2012).

Diante do exposto, emerge a seguinte pergunta de pesquisa: Qual o grau de eficiência da gestão de recursos públicos destinados à educação nos anos iniciais do ensino fundamental nos municípios do Sudoeste do Paraná? Para responder essa questão, definiu-se como objetivo deste trabalho: Analisar o grau de eficiência na utilização dos recursos públicos destinados aos anos iniciais do ensino fundamental nas escolas públicas de responsabilidade dos municípios do Sudoeste do Paraná.

Este trabalho limita-se a analisar a eficiência na utilização dos recursos públicos com educação dos quarenta e dois (42) municípios da região Sudoeste do Paraná, visto que o Paraná foi um dos estados que apresentou no decorrer das avaliações do Índice de Desenvolvimento da Educação Básica (IDEB) aumento nas médias alcançadas, e sendo a região Sudoeste uma das que ultrapassou as médias projetadas na maioria dos municípios, delimitou-se essa região para o estudo, a fim de analisar uma região em específico. No contexto de educação, delimitaram-se para análise os primeiros anos do ensino fundamental $\left(1^{\circ}\right.$ ao $5^{\circ}$ ano $)$, por serem os anos oferecidos pelas escolas públicas de responsabilidade municipal, visto que, os últimos 
anos do ensino fundamental pertencem ao âmbito estadual de ensino. A fim de garantir comparação entre períodos, quanto à delimitação temporal, realizou-se a análise de quatro anos onde foram utilizados dados referentes aos anos de 2013, 2015, 2017 e 2019, por compreenderem a divulgação das avaliações do IDEB, a qual é publicada ao final de cada dois (2) anos.

Para isso a pesquisa utilizou-se da ferramenta matemática Análise Envoltória de Dados (DEA), a qual usa de conceitos de programação linear para medir a eficiência do sistema. Para o cálculo da eficiência foram utilizadas variáveis de entrada (inputs ou insumos) e saída (outputs ou produtos). Como variáveis de entrada foram utilizados dados da despesa empenhada com ensino fundamental, a qual foi utilizada por demonstrar o quanto de recursos financeiros foram destinados para função no período, permitindo posteriormente analisar se os mesmos estão sendo alocados corretamente.

Classificaram-se ainda como inputs o número de matrículas a qual permite identificar a quantidade de alunos atendidos e analisar se os demais recursos estão sendo adequadamente alocados, por fim, como variáveis de entrada foram utilizadas o número de docentes e escolas que cada município possui na função, visto que a quantidade de professores e infraestrutura estão relacionadas com a qualidade de ensino ofertado. Como variável de saída, para o cálculo da eficiência, foram utilizadas as notas que cada município alcançou na avaliação do IDEB de cada período.

Do ponto de vista prático, a pesquisa justifica-se por demonstrar para a sociedade a necessária transparência sobre a gestão do sistema educacional público e propiciar a fiscalização dos orçamentos públicos educacionais executados. Evidenciando, desta maneira, se os recursos alocados em políticas públicas estão repercutindo eficientemente. Para Besen et al. (2017), a educação é um elemento essencial para o progresso da sociedade, tornando necessário saber se o governo está investindo recursos de forma satisfatória e eficiente, com isso, a pesquisa justifica-se por permitir aos governantes e gestores públicos identificar o reflexo dos recursos alocados no setor, possibilitando que o governo possa desenvolver políticas mais assertivas para melhorar o aproveitamento dos gastos e recursos disponíveis.

Do ponto de vista teórico, justifica-se pela contribuição que traz para comunidade científica em evidenciar a necessidade de realizar mais avaliações de eficiência na área de gestão pública. Demonstra ainda, a possibilidade de utilizar métodos quantitativos como instrumentos metodológicos para medir o desempenho, provocando assim o interesse do meio acadêmico para o estudo de um tema que apresenta cada vez mais relevância no contexto econômico e social.

Ainda quanto à contribuição teórica, justifica-se por promover, para a comunidade acadêmica, maior conhecimento quanto à utilização e alocação dos gastos públicos, possibilitando, assim, informações relevantes e atuais sobre a temática, contribuindo com conteúdo para estudos sobre a gestão dos gastos na área pública. Ademais, contribui para estudos que visam analisar a eficiência de processos produtivos, podendo ser aplicados para avaliar a utilização e melhorar o aproveitamento de recursos tanto no setor público, quanto no privado.

Estudos anteriores, analisaram a eficiência na alocação dos recursos públicos em educação, Amaral, Santos e Santos (2019) no estado do Rio de Janeiro e Monte e Leopoldino (2017) no estado do Ceará, investigando os anos iniciais e finais do ensino fundamental e apresentaram como delimitação tempo o período de um ano. Mattei e Bezerra (2018) nos municípios do estado de Santa Catarina e Savian e Bezerra (2013) os municípios do Paraná, analisando os anos iniciais do ensino fundamental, no período de dois anos. Besen et al. (2017) avaliaram a eficiência dos estados brasileiros no ano de 2013, onde limitaram-se a investigar a educação no contexto do ensino médio. Rech, Comunelo e Godarth (2014) e Bohrer, Comunelo 
e Godarth (2013) investigaram a eficiência em específico da região Sudoeste do Paraná.

A presente pesquisa difere-se dos estudos anteriores por utilizar como delimitação temporal maior quantidade de anos investigados, o que permite analisar as diferenças de resultados em um período maior de tempo, enquanto, que dos estudos de Rech et al. (2014) e Bohrer et al. (2013) que apresentam a mesma amostra de pesquisa, além do período temporal, o presente estudo difere-se por utilizar maior diversidade de variáveis de entrada, sendo possível identificar a interferência de outros fatores no resultado da eficiência.

Além dessa introdução, este artigo conta com referencial teórico apresentado na seção 2; a metodologia discutida na seção 3; na seção 4 são apresentados e discutidos os resultados e por fim, são tecidas considerações finais na seção 5. Ao final, as referências que deram base a esta pesquisa são apresentadas.

\section{REFERENCIAL TEÓRICO}

\subsection{Orçamento Público}

Apresentando origens na necessidade de controlar e autorizar a aplicação do dinheiro público, o orçamento público está interligado ao desenvolvimento da democracia, e trata-se de uma espécie de delegação para que os representantes do povo possam, em seu nome, efetuar o dispêndio dos recursos públicos (C. L. Oliveira \& Ferreira, 2017). Segundo Kohama (2017), todo processo de planejamento e orçamentação é abastecido de informações provenientes da Contabilidade Pública, a qual serve de instrumento à Administração proporcionando controles necessários à melhor condução dos negócios públicos.

Ainda de acordo com Kohama (2017), o governo tem como responsabilidade garantir o bem estar à coletividade, e para isso faz uso de técnicas de planejamento e programas de ações, as quais são condensadas no chamado Sistema de Planejamento Integrado, também conhecido como Planejamento-Orçamento que busca por meio de escolhas alternativas prioritárias, o melhor emprego dos meios disponíveis para minimizar os problemas econômicos e sociais existentes:

\footnotetext{
O orçamento é o processo pelo qual se elabora expressa, executa e avalia o nível de cumprimento da quase totalidade do programa de governo para cada período orçamentário. É um instrumento de governo, de administração e de efetivação e execução dos planos gerais de desenvolvimento socioeconômico (Kohama, 2017, p. 46).
}

O processo orçamentário, conforme com Telles, Suguihiro e Barros (2011), é composto por leis previstas constitucionalmente, com o objetivo de garantir a realização de ações articuladas do planejamento e da organização financeira estatal. As leis reguladoras da atividade orçamentária federal são o Plano Plurianual (PPA), a Lei de Diretrizes Orçamentárias (LDO) e a Lei Orçamentária Anual (LOA).

De acordo com Couto, Barbosa e Resende (2018), é por meio do orçamento que se identifica de onde virão os recursos públicos e onde serão alocados, sejam em gastos ou investimentos públicos. Sendo o planejamento o ponto de partida e processo fundamental para uma administração eficiente, uma vez que a qualidade do planejamento determinará os rumos para uma má ou boa gestão, a qual está diretamente ligada ao bem estar da sociedade.

Para Santos e Camacho (2014), as atuais mudanças na conjuntura econômica do país exigem que as organizações aperfeiçoem seus métodos de planejamento, controle e avaliação, a fim de garantir que seus objetivos sejam alcançados. Empregando dessa maneira, responsabilidade à elaboração do orçamento, uma vez que ele é a principal ferramenta de planejamento, por estarem estabelecidas as metas desejadas e os recursos disponíveis. 


\subsection{Educação e Políticas Públicas}

Besen et al. (2017) afirmam que a educação se configura como um fator diferencial, por meio do qual o indivíduo consegue aumentar sua renda, diminuir a pobreza, aumentando a produtividade e a velocidade do crescimento econômico local. Segundo Mattei e Bezerra (2018, p. 28), "uma sociedade com maior nível de escolaridade tende a ser mais produtiva economicamente, mais consciente politicamente e menos desigual socialmente".

De acordo com o art. 205 da Constituição do Brasil (1988), a educação é "direito de todos e dever do Estado e da família [...]”. Segundo Savian e Bezerra (2013), a manutenção de programas de educação infantil e de ensino fundamental é de competência dos municípios, os quais devem atuar com a contribuição técnica e financeira da União e do Estado.

As discussões sobre políticas públicas tomaram nos últimos anos uma dimensão muito ampla. Para A. F. Oliveira (2010), isso se deu devido ao avanço das condições democráticas em todo o mundo e por conta da gama de arranjos institucionais de governos. Podendo existir políticas públicas em diversas áreas, enfatiza-se que políticas educacionais possuem foco específico do tratamento da educação, que em geral se aplica às questões escolares.

Atualmente na aplicação de recursos públicos na área de educação básica, os gestores públicos estão submetidos a um conjunto de políticas/programas que orientam suas ações. Contudo, apesar da concretização de políticas públicas educacionais ser essencial, para melhoria da qualidade da educação, professores capacitados, estruturas físicas adequadas e materiais de qualidade são o ponto de partida para qualidade da educação básica (Lourenço, Angotti, Nascimento, \& Sauerbronn, 2017; Mattei \& Bezerra, 2018).

\subsection{1 Índice de Desenvolvimento da Educação Básica - IDEB}

O IDEB foi criado pelo Instituto Nacional de Estudos e Pesquisas Educacionais Anísio Teixeira (INEP) no ano de 2007, com a finalidade de reunir em um só indicador a combinação de dois fatores que interferem na qualidade da educação, sendo eles: I) os indicadores de fluxo medidos pelo Censo Escolar, como taxa de aprovação, reprovação e evasão; e, II) os indicadores de desempenho em exames padronizados, como o Sistema de Avaliação da Educação Básica (SAEB) e a Prova Brasil, os quais são executados a cada dois anos ao fim de determinada etapa da educação básica (Paz \& Raphae, 2012).

A Prova Brasil e o SAEB são avaliações de larga escala, onde os testes são realizados no quinto e nono ano do ensino fundamental e na terceira série do ensino médio, em que são aplicados questionários de Língua Portuguesa, Matemática e questionários socioeconômicos. Após os testes o índice do IDEB é calculado em média de 0 a 10, apurado separadamente para ensino fundamental e médio, em valores por escolas, por rede estadual, municipal, pública e privada, total por Município, Estado e Total para o Brasil (Paz \& Raphae, 2012; Besen et al., 2017).

De acordo com Paz e Raphae (2012), o Brasil tem como meta, estabelecida pelo Ministério da Educação (MEC), alcançar, até 2021, níveis educacionais de países desenvolvidos, atingindo para isso a média seis (6) para os anos iniciais do ensino fundamental. Cabe ressaltar que, a criação das metas teve como ponto de partida os resultados dos dados de desempenho das primeiras avaliações, onde desde então se projeta a meta do próximo ano com base na avaliação anterior.

Segundo M. C. Silva, Souza, Silva e Borges (2016), o IDEB se configura como um dispositivo que avalia a aprendizagem da educação básica do país, e foi designado à nação como instrumento inovador de aferição de resultados educacionais de Estados, Municípios, redes de ensino e escolas, com o objetivo de melhorar a qualidade na educação básica brasileira. 


\subsection{Eficiência na Gestão da Educação}

Todos os setores apresentam recursos patrimoniais e humanos escassos para atender às crescentes necessidades dos clientes, exigindo que os tomadores de decisão, no desenvolvimento de suas atividades, procurem a melhor combinação dos recursos e a constante busca pela eficiência, a qual se conceitua pela combinação otimizada dos métodos e insumos (inputs) necessários no processo produtivo de maneira que gerem o máximo de produto (output) (Peña, 2008).

O Estado tem a responsabilidade de agir de modo a maximizar o bem estar da coletividade e os níveis de desenvolvimento socioeconômico. Pertencendo aos governos locais o dever pela provisão de diversos bens cuja oferta é realizada de forma limitada pelo mercado. Atender as necessidades da população faz com que os gestores públicos levem em conta a natureza limitada desses recursos e avaliem a forma racional de utilizá-los, buscando privilegiar a eficiência e a avaliação do setor público de maneira que os tributos arrecadados da sociedade retornem a mesma com o fornecimento de bens e serviços de qualidade (Amorim, Diniz, Lima, \& Amorim, 2016).

Considerando que os reflexos dos recursos públicos alocados nos diversos setores devem ser transformados em serviços de qualidade e influenciar no crescimento dos indicadores da população, realizar a avaliação da eficiência em âmbito público é essencial e deve ser adotada por seus gestores. Sendo que a gestão pública é considerada eficiente quando se obtêm os resultados definidos em suas metas e objetivos, gastando menos recursos, o que reflete na transformação de insumos em serviços e produtos de qualidade oferecidos a população (F. J. V. Souza et al., 2012).

Pode-se dizer que a avaliação e a melhoria na qualidade dos gastos públicos dos diferentes níveis de governo tem sido uma das grandes preocupações da literatura e da prática de finanças públicas nos últimos anos. Adicionalmente, a educação é um dos setores a receber atenção especial por ser um dos serviços mais providos pelo setor público, por exercer papel importante para o aperfeiçoamento do capital humano, e apresentar relação direta com o desenvolvimento social da população, por meio da qual ela adquire conhecimentos e desenvolve a consciência crítica (Boueri, Rocha, \& Rodopoulos, 2015; F. J. V. Souza et al., 2012).

Para Savian e Bezerra (2013), avaliar a eficiência é importante por construir fronteiras de eficiência e detectar situações de ineficiência, podendo assim existir a possibilidade de melhorar a desempenho dos municípios ineficientes futuramente. Sendo, pois a educação um fator essencial para o crescimento e desenvolvimento de uma nação, se faz necessário e importante saber se o governo está investindo recursos de forma eficiente e satisfatória, podendo dessa maneira desenvolver políticas de melhoria para a educação.

\subsection{Estudos Similares}

Os estudos similares que já abordaram o tema em estudo e foram recorrentes como embasamento teórico para a construção desta pesquisa estão descritos na Tabela 1.

Tabela 1. Estudos similares

\begin{tabular}{|c|c|c|c|}
\hline $\begin{array}{l}\text { Autores/ } \\
\text { Ano }\end{array}$ & $\begin{array}{c}\text { Objetivo da pesquisa e } \\
\text { metodologia }\end{array}$ & Indicadores & Achados da pesquisa \\
\hline $\begin{array}{l}\text { Amaral et } \\
\text { al. }(2019)\end{array}$ & $\begin{array}{l}\text { Analisar o nível de eficiência } \\
\text { na gestão dos gastos aplicados } \\
\text { na área de educação do ensino } \\
\text { fundamental no estado do Rio } \\
\text { de Janeiro no ano de } 2017 \text {, } \\
\text { utilizando a ferramenta }\end{array}$ & $\begin{array}{l}\text { Inputs: Índice de Gastos no } \\
\text { Ensino Fundamental; Índice } \\
\text { de Funções Docentes no } \\
\text { Ensino Fundamental; Índice } \\
\text { de Estabelecimentos de } \\
\text { Ensino Fundamental. }\end{array}$ & $\begin{array}{l}\text { Apenas } 10,3 \% \text { das cidades são } \\
\text { eficientes na gestão dos gastos, } \\
\text { revelando que há necessidade de } \\
\text { melhoria na gestão educacional } \\
\text { possibilitando melhor retorno dos } \\
\text { recursos destinados à educação. }\end{array}$ \\
\hline
\end{tabular}




\begin{tabular}{|c|c|c|c|}
\hline & Análise Envoltória de Dados. & Outputs: IDEB e TAEF. & \\
\hline $\begin{array}{l}\text { Mattei } \\
\text { Bezerra } \\
(2018)\end{array}$ & $\begin{array}{l}\text { Analisar a eficiência dos gastos } \\
\text { públicos nos municípios } \\
\text { catarinenses em alocar seus } \\
\text { recursos nos anos iniciais do } \\
\text { ensino fundamental, durante } \\
2007 \text { e } 2011 \text { utilizando a DEA. }\end{array}$ & $\begin{array}{l}\text { Inputs: Despesas por aluno; } \\
\text { número de escolas e docentes } \\
\text { de cada município; Produto } \\
\text { Interno Bruto (PIB) per } \\
\text { capita municipal. } \\
\text { Outputs: IDEB. }\end{array}$ & $\begin{array}{l}\text { A grande maioria dos municípios } \\
\text { catarinenses não aloca de forma } \\
\text { eficiente seus recursos. Sendo os } \\
\text { municípios menores os mais } \\
\text { eficientes do que os municípios } \\
\text { mais populosos. }\end{array}$ \\
\hline $\begin{array}{l}\text { Besen et al. } \\
(2017)\end{array}$ & $\begin{array}{l}\text { Medir o grau de eficiência dos } \\
\text { Estados Brasileiros na } \\
\text { alocação dos gastos com } \\
\text { Educação no Ensino Médio no } \\
\text { ano de 2013, através do uso da } \\
\text { ferramenta DEA. }\end{array}$ & $\begin{array}{l}\text { Inputs: Orçamento por } \\
\text { aluno; Índices de professores } \\
\text { com Ensino Superior. } \\
\text { Outputs: IDEB, taxas de } \\
\text { aprovação, reprovação e de } \\
\text { abandono. }\end{array}$ & $\begin{array}{l}\text { Apenas dois Estados obtiveram o } \\
\text { nível máximo de eficiência, } \\
\text { representando } 7,69 \% \text { da amostra, } \\
\text { verificando-se que os } \\
\text { governantes não estão alocando } \\
\text { os recursos de forma eficiente. }\end{array}$ \\
\hline $\begin{array}{l}\text { Monte e } \\
\text { Leopoldino } \\
(2017)\end{array}$ & $\begin{array}{l}\text { Avaliar a eficiência dos gastos } \\
\text { em educação realizados pelos } \\
\text { municípios cearenses no } \\
\text { exercício 2015, utilizando a } \\
\text { Análise Envoltória de Dados. }\end{array}$ & $\begin{array}{l}\text { Inputs: Valores } \\
\text { investimento por de } \\
\text { matriculado. } \\
\text { Outputs: IDEB. }\end{array}$ & $\begin{array}{l}\text { Apenas três municípios da } \\
\text { amostra foram considerados } \\
\text { eficientes. Conclui-se que os } \\
\text { municípios cearenses possuem } \\
\text { considerável margem para de } \\
\text { melhoria na alocação dos } \\
\text { recursos disponíveis. }\end{array}$ \\
\hline $\begin{array}{l}\text { Rech et al. } \\
(2014)\end{array}$ & $\begin{array}{l}\text { Investigar a eficiência do gasto } \\
\text { público com a educação } \\
\text { referente ao ano de } 2011 \text { nas } \\
\text { cidades do Sudoeste do Paraná, } \\
\text { utilizando a Análise Envoltória } \\
\text { de Dados. }\end{array}$ & $\begin{array}{l}\text { Inputs: Gasto aluno. } \\
\text { Outputs: Nota média na } \\
\text { Prova Brasil. }\end{array}$ & $\begin{array}{l}\text { Identificaram que os municípios } \\
\text { que possuem os maiores gastos } \\
\text { por aluno, não figuram nas } \\
\text { primeiras posições da eficiência. }\end{array}$ \\
\hline $\begin{array}{l}\text { Savian } \\
\text { Bezerra } \\
(2013)\end{array}$ & $\begin{array}{l}\text { Avaliar a eficiência dos gastos } \\
\text { públicos com a educação nas } \\
\text { séries iniciais do ensino } \\
\text { fundamental nos municípios } \\
\text { do Estado do Paraná, nos anos } \\
\text { de } 2005 \text { e } 2009 \text {, através da } \\
\text { aplicação da técnica Análise } \\
\text { Envoltória de Dados. }\end{array}$ & $\begin{array}{l}\text { Inputs: PIB per capita } \\
\text { municipal; Despesa por } \\
\text { aluno matriculado; Número } \\
\text { de matrículas no ensino } \\
\text { fundamental em escolas } \\
\text { municipais e número de } \\
\text { docentes de cada município. } \\
\text { Outputs: IDEB }\end{array}$ & $\begin{array}{l}\text { Na maioria dos municípios } \\
\text { paranaenses analisados pela } \\
\text { pesquisa os gastos públicos com } \\
\text { educação se mostraram } \\
\text { ineficientes, o que demonstra a } \\
\text { necessidade de revisão, por parte } \\
\text { da administração pública, dos } \\
\text { meios de alocação dos recursos. }\end{array}$ \\
\hline $\begin{array}{l}\text { Bohrer et al. } \\
(2013)\end{array}$ & $\begin{array}{l}\text { Investigar a eficiência do gasto } \\
\text { público com a educação } \\
\text { referente ao ano de } 2009 \text { nas } \\
\text { cidades do Sudoeste do Paraná } \\
\text { com a utilização da Análise } \\
\text { Envoltória de Dados. }\end{array}$ & $\begin{array}{l}\text { Inputs: Custo aluno. } \\
\text { Outputs: Nota média na } \\
\text { Prova Brasil. }\end{array}$ & $\begin{array}{l}\text { Os municípios que possuem os } \\
\text { maiores custos por aluno, não } \\
\text { figuram nas primeiras posições da } \\
\text { eficiência na gestão dos gastos } \\
\text { com educação. }\end{array}$ \\
\hline
\end{tabular}

Fonte: Elaborado pelas autoras (2020).

Avaliaram a eficiência na utilização dos gastos em educação, Amaral et al. (2019) no estado do Rio de Janeiro e Monte e Leopoldino (2017) no estado do Ceará, investigaram os anos iniciais e finais do ensino fundamental e apresentaram como delimitação tempo o período de um ano. Em seus achados identificaram que a quantidade de municípios eficientes é pequena. Ao analisar a eficiência dos gastos públicos em educação, Mattei e Bezerra (2018) nos municípios do estado de Santa Catarina e Savian e Bezerra (2013) os municípios do Paraná, analisaram os anos iniciais do ensino fundamental, no período de dois anos. Os autores identificaram que nos dois estados a maioria dos municípios não aloca seus recursos de forma eficiente.

Besen et al. (2017) avaliaram a eficiência dos estados brasileiros no ano de 2013, contudo, diferente dos outros estudos precedentes, investigaram a educação referente ao ensino médio. Em seus achados, assim como no âmbito municipal analisado pelas outras pesquisas, os resultados demonstram que a quantidade de estados que alçaram a eficiência na alocação dos gastos em educação é pequena. Rech et al. (2014) e Bohrer et al. (2013) investigaram a 
eficiência em específico da região Sudoeste do Paraná, e limitaram-se a análise de um período. Os autores utilizaram como variáveis para o cálculo da eficiência o gasto por aluno e alcançaram resultados similares, demonstrando que a maioria dos municípios da região não aloca seus recursos com eficiência.

Diante dos estudos de Amaral et al. (2019), Mattei e Bezerra (2018), Besen et al. (2017), Monte e Leopoldino (2017) e Savian e Bezerra (2013) a presente pesquisa diferencia-se por analisar a eficiência na utilização dos recursos públicos nos anos iniciais do ensino fundamental de uma região em específico, e por comparar o período de quatro anos. Diante dos estudos de Rech et al. (2014) e Bohrer et al. (2013) que possuem a mesma amostra de municípios investigada pela presente pesquisa, o presente estudo se diferencia por analisar a comparação dos resultados de quatro anos e utilizar para calcular a eficiência mais variáveis de entrada, sendo elas o número de matrículas e docentes, e como saída a nota do IDEB.

\section{METODOLOGIA}

\subsection{Procedimentos para coleta e análise dos dados}

Os anos analisados pela presente pesquisa foram 2013, 2015, 2017 e 2019, os quais foram selecionados por compreender a divulgação das avaliações do Índice de Desenvolvimento da Educação Básica (IDEB), a qual é publicada ao final de cada dois (2) anos. A amostra da presente pesquisa é composta pelos municípios do Sudoeste do Paraná, que de acordo com o Instituto Paranaense de Desenvolvimento Econômico e Social [IPARDES] (2020), é composto por quarenta e dois (42) municípios como consta na Figura 1.

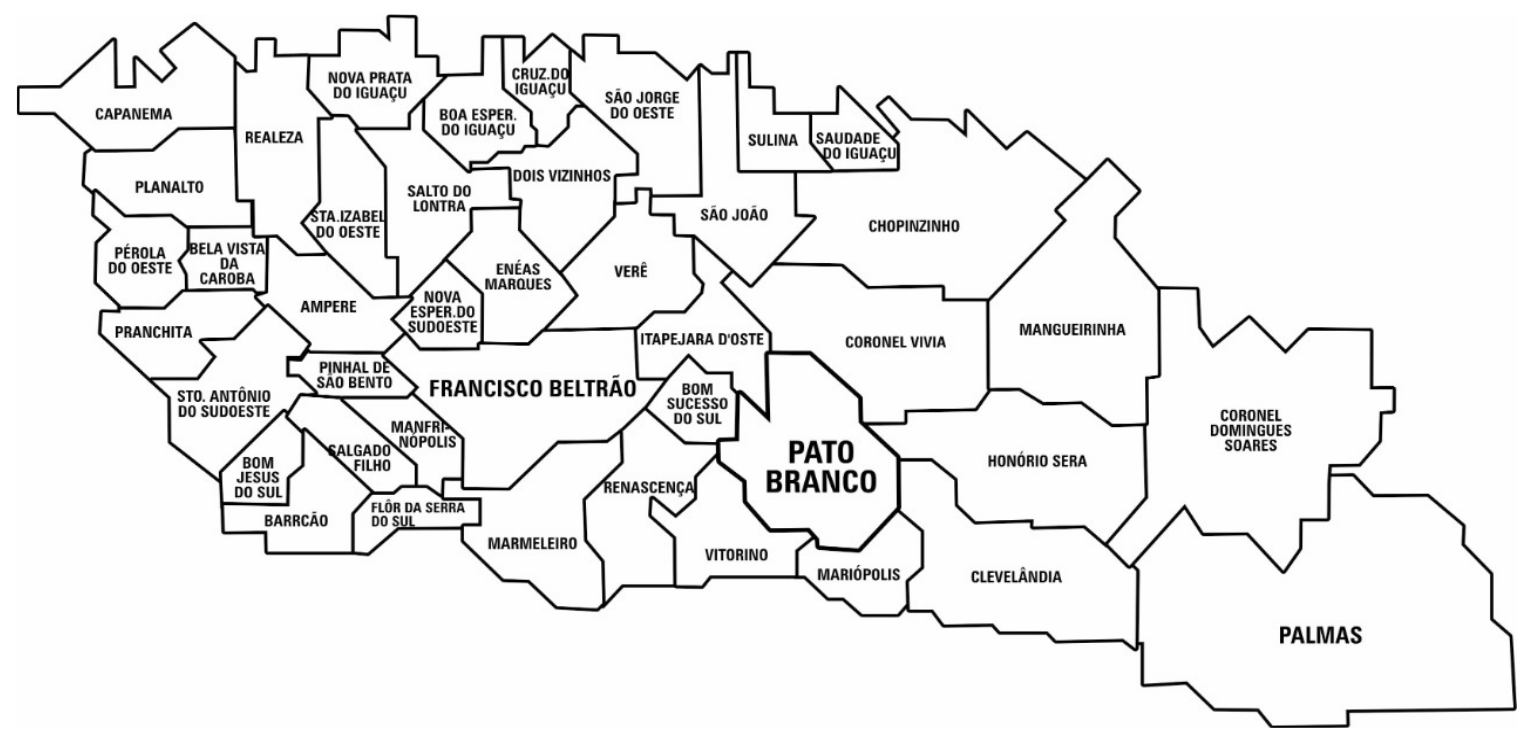

Figura 1. Mapa do Sudoeste do Paraná Fonte: Procópio (2020).

Desses municípios, apresentados na Figura 1, foram coletados inicialmente os valores financeiros destinados ao ensino fundamental. Essas informações foram obtidas com acesso ao site do Sistema de Informações Contábeis e Fiscais do Setor Público Brasileiro (SICONFI) (https://siconfi.tesouro.gov.br/). Dentro no site, o acesso se deu por meio da aba "Consultas", "Consultas Finbra" "Contas Anuais", na qual foi retirado o relatório de Despesas por Função dos municípios nos exercícios de 2013, 2015, 2017 e 2019.

Dentro do relatório de Despesas por Função foram coletados os valores referentes às despesas empenhadas com educação, em específico com o ensino fundamental por cada uma das prefeituras dos municípios do Sudoeste do Paraná, levantando, desta maneira, quais os 
recursos financeiros destinado para educação em cada município.

As informações sobre quantidade de escolas em cada município, assim como a quantidade de matrículas e docentes pertencentes a essas escolas dos períodos de 2013, 2015 e 2017 foram extraídas do Instituto Brasileiro de Geografia e Estatística (IBGE), via site (https://cidades.ibge.gov.br/), enquanto que as informações referentes ao ano de 2019 foram coletadas do INEP, via site (http://inep.gov.br/sinopses-estatisticas-da-educacao-basica), diante do documento Sinopse Estatística da Educação Básica.

Cabe salientar que, os dados referentes a quantidades de matrículas e docentes foram coletados dentro da esfera municipal de ensino, em virtude de que os primeiros anos do ensino fundamental $\left(1^{\circ}\right.$ ao $5^{\circ}$ ano) estão sob responsabilidade dos municípios. Assim como a quantidade de escolas que foram coletadas relativas aos anos iniciais do ensino fundamental em âmbito municipal.

As notas obtidas por cada município nas avaliações do IDEB e as metas projetadas para cada município durante as avaliações, foram coletadas por meio do site do INEP em específico no Portal do IDEB (http://portal.inep.gov.br/ideb). As notas obtidas por cada um dos municípios e suas respectivas metas foram coletadas referentes às avaliações realizadas aos anos iniciais do ensino fundamental diante da Rede/Dependência administrativa municipal.

Os dados referentes os recursos financeiros caracterizados como as despesas com o ensino fundamental, os recursos físicos/materiais classificados como o número de escolas municipais de ensino fundamental, e os recursos humanos sendo o número de matrículas e docentes pertencentes aos anos iniciais do ensino fundamental em cada município, e as notas obtidas no IDEB por cada um deles, foram dispostos em tabelas com uso do software Microsoft Excel, por meio das quais se realizou inicialmente a análise descritiva dos dados e valores apurados.

Cabe salientar que, fez-se necessário excluir da análise descritiva e do cálculo da eficiência no ano de 2013 o município de Nova Esperança do Sudoeste, por não possuir dados no relatório de despesas por função com ensino fundamental naquele ano, e no ano de 2015 o município de Pinhal de São Bento, por não dispor de nota no IDEB no período.

Posteriormente para análise dos dados e cálculo da eficiência foi utilizada a ferramenta estatística Análise Envoltória de Dados (DEA), onde foram classificados como unidades tomadoras de decisão (Decision Making Units - DMU) os quarenta e dois (42) municípios da amostra, e as informações obtidas por meio do levantamento de dados foram especificados como variáveis para o cálculo da eficiência.

As variáveis foram divididas em inputs (insumos) e outputs (produtos), sendo inputs as despesas com o ensino fundamental, os recursos físicos/materiais o número de escolas municipais de ensino fundamental, e o número de matrículas e docentes pertencentes aos anos iniciais do ensino fundamental em cada município, enquanto que notas obtidas no IDEB por cada um deles, como output.

Diante dessas variáveis os dados foram rodados na ferramenta DEA foi utilizado o Sistema Integrado de Apoio à Decisão (SIAD), que de acordo com Meza, Biondi, Mello e Gomes (2005), foi desenvolvido para calcular todos os modelos clássicos da DEA.

Diante dos resultados obtidos por meio da ferramenta, os índices de eficiência foram classificados conforme os parâmetros usados por Savian e Bezerra (2013) e Monte e Leopoldino (2017): classificadas como eficientes as unidades com o resultado 1,000 o qual corresponde à pontuação máxima, os municípios cujos índices entre 0,800 e 0,999 foram consideradas com ineficiência fraca, as que obtiveram índices que variaram de 0,600 a 0,799 com ineficiência moderada, enquanto que as unidades com eficiência até 0,599 são classificadas com ineficiência forte. 


\subsection{Análise Envoltória de Dados}

O método escolhido para mensurar a eficiência da utilização dos recursos públicos com educação nos anos iniciais do ensino fundamental nos municípios da amostra foi a Análise Envoltória de Dados (DEA- sigla em inglês de Data Envelopment Analysis), um método não paramétrico que utiliza de conceitos de programação linear para avaliar a eficiência das unidades produtivas, as chamadas Unidades Tomadoras de Decisão (DMU - do inglês Decision Making Units), realizando a comparação de entidades que realizam tarefas similares e se diferem pela quantidade de insumos empregados (inputs) e produtos obtidos (outputs) (Peña, 2008; P. C. T. Souza \& Wilhelm, 2009; J. L. M. Silva \& Almeida, 2012).

De acordo com Peña (2008), o DEA configura-se como um método não paramétrico, ou seja, estabelece uma curva de eficiência por meio de programação matemática de otimização, não requerendo a determinação de nenhuma relação funcional entre insumos e produtos. A técnica teve início do seu desenvolvimento em 1978 na tese de doutoramento de Edwardo Rhodes com orientação de W. W. Cooper, onde a pesquisa objetivou avaliar o desempenho de escolas públicas americanas, originando o modelo CCR do DEA (Nova \& Santos, 2008).

A ferramenta DEA busca avaliar o desempenho das DMU's, identificando as que melhor aproveitam os insumos na produção de resultados, calculando um índice de eficiência para as DMU's baseado em uma ponderação entre insumos e resultados, e, utiliza-o como padrão comparativo para o cálculo de eficiência das demais unidades organizacionais, atribuindo a cada DMU um valor referente ao seu desempenho relativo, valores que variam entre 0 e $100 \%$ ou 0 e 1 , no qual as unidades eficientes recebem valor igual a 1 ou $100 \%$ (Monte \& Leopoldino, 2017; Savian \& Bezerra, 2013; P. C. T. Souza \& Wihelm, 2009).

A técnica DEA tem sido amplamente utilizada no estudo da eficiência da administração pública e organizações sem fins lucrativos, como estabelecimentos de saúde, esportes, transporte, redes de restaurantes, franquias, instituições culturais e departamentos educacionais. A ferramenta auxilia os gestores na tomada de decisão por identificar as DMU's eficientes, medir e localizar as ineficiências, além de estabelecer taxas de substituição de entradas e saídas buscando maximizar a eficiência (Besen et al., 2017; P. C. T. Souza \& Wihelm, 2009; Peña, 2008).

A presente pesquisa utilizará na análise DEA, o modelo criado em 1984 por Banker, Charnes e Cooper, o BCC ou VRS (Variable Returns of Scale), que de acordo com Mattei e Bezerra (2018), trabalha com retornos variáveis de escala e é indicado para comparar unidades semelhantes, uma vez que, o modelo analisa um grande número de observações. Quanto à orientação, o presente trabalho orientou o modelo BCC a output, ou seja, orientação-produto que de acordo com A. A. P. Silva, Ferreira, Braga e Abrantes (2012), busca maximizar o aumento nos níveis de produtos, mantendo fixa a quantidade de insumos.

\section{APRESENTAÇÃO E DISCUSSÃO DOS RESULTADOS}

\subsection{Análise Descritiva dos Dados}

A Tabela 2 apresenta os municípios que se destacaram quanto aos recursos financeiros nos quatro períodos analisados. Os municípios que apresentaram as maiores despesas com a função ensino fundamental, durante os quatro anos investigados foram Pato Branco, Francisco Beltrão e Palmas, respectivamente. Enquanto que os que destinaram as menores quantias de recursos financeiros durante os anos analisados foram Sulina, Bela Vista da Caroba e Boa Esperança do Iguaçu. 
Tabela 2. Despesas com ensino fundamental

\begin{tabular}{|c|c|c|c|c|c|}
\hline \multirow{3}{*}{ Municípios } & \multicolumn{4}{|c|}{ Período } & \multirow{2}{*}{$\begin{array}{l}\text { Montante tota } \\
\text { investido }\end{array}$} \\
\hline & 2013 & 2015 & 2017 & 2019 & \\
\hline & $\mathbf{R} \$$ & $\mathbf{R} \$$ & R\$ & $\mathbf{R} \$$ & $\mathbf{R} \$$ \\
\hline Pato Branco & $36.098 .823,92$ & $47.004 .537,07$ & $49.898 .610,26$ & $46.486 .027,61$ & $179.487 .998,86$ \\
\hline Francisco Beltrão & $26.290 .782,52$ & $33.100 .468,63$ & $36.824 .540,46$ & $42.002 .517,06$ & $138.218 .308,67$ \\
\hline Palmas & $22.826 .667,35$ & $24.370 .091,42$ & $32.746 .821,02$ & $36.432 .354,95$ & $116.375 .934,74$ \\
\hline Vitorino & $1.780 .367,42$ & $3.959 .930,21$ & $4.392 .494,72$ & $4.985 .336,28$ & $15.118 .128,63$ \\
\hline Manfrinópolis & $3.041 .269,50$ & $2.836 .985,75$ & $2.828 .823,15$ & $2.826 .483,83$ & $11.533 .562,23$ \\
\hline Sulina & $2.677 .755,31$ & $2.207 .653,50$ & $2.620 .442,33$ & $2.885 .830,01$ & $10.391 .681,15$ \\
\hline Bela Vista da Caroba & $1.902 .083,30$ & $3.303 .740,27$ & $2.073 .151,26$ & $1.951 .293,65$ & $9.230 .268,48$ \\
\hline Boa Esperança do Iguaçu & $1.693 .829,60$ & $2.139 .218,43$ & $258.114,29$ & $2.708 .420,97$ & $6.799 .583,29$ \\
\hline
\end{tabular}

Fonte: Elaborado pelas autoras com dados coletados no Siconfi (2020). Valores em Reais (R\$).

Destacaram-se ainda na Tabela 2, os municípios de Vitorino com a maior variação de valores entre os municípios analisados, durante os quatro anos, onde partiu de $\mathrm{R} \$ 1.780 .367,42$ no primeiro período e destinou no último ano $\mathrm{R} \$ 4.985 .336,28$, caracterizando um aumento de aproximadamente $180 \%$. E apresentando a menor variação dentre os municípios analisados e classificando-se ainda como o único município que apresentou diminuição nos valores destinados para educação está Manfrinópolis.

A Tabela 3 traz os valores referentes aos gastos por aluno, que se deu pela divisão das despesas pela quantidade de matrículas que cada município apresentou no mesmo ano.

Tabela 3. Gastos por aluno

\begin{tabular}{l|c|c|c|c}
\hline \multirow{2}{*}{\multicolumn{1}{c}{ Municípios }} & \multicolumn{4}{c}{ Período } \\
\cline { 2 - 5 } & $\mathbf{2 0 1 3}$ & $\mathbf{2 0 1 5}$ & $\mathbf{2 0 1 7}$ & $\mathbf{2 0 1 9}$ \\
\cline { 2 - 5 } & $\mathbf{R} \mathbf{R}$ & $\mathbf{R}$ & $\mathbf{R} \mathbf{R}$ & $\mathbf{R}$ \\
\hline São Jorge D' Oeste & $10.199,04$ & $14.844,85$ & $16.010,28$ & $19.283,09$ \\
\hline Manfrinópolis & $12.941,57$ & $13.134,19$ & $15.290,94$ & $15.615,93$ \\
\hline São João & $8.948,07$ & $17.147,65$ & $14.416,00$ & $15.406,33$ \\
\hline Francisco Beltrão & $4.905,00$ & $6.263,10$ & $7.322,44$ & $7.977,69$ \\
\hline
\end{tabular}

Fonte: Elaborado pelas autoras com dados coletados no IBGE; INEP e Siconfi (2020). Valores em Reais (R\$).

Por meio da Tabela 3, pode-se observar o município de Francisco Beltrão que se destacou nos quatro anos analisados com o menor gasto por aluno da amostra. Destacaram-se também, os municípios de São Jorge D' Oeste, Manfrinópolis e São João, com os maiores gastos por aluno dentre os municípios analisados. Pode-se verificar ainda que todos os municípios da amostra apresentaram gastos por alunos próximos aos apresentados pelos demais.

Ao analisar as variações das estatísticas descritivas das despesas empregadas na função conforme demonstra a Tabela 4, pode-se observar que a média de valores destinados para a função apresentou aumento durante os anos analisados, da mesma forma que, o valor máximo empregado na função. Identificou-se também que, o valor mínimo, por sua vez, apresentou oscilação para mais e para menos no período analisado. O desvio padrão, por sua vez, apresentou durante os quatro períodos valores altos, demonstrando a disparidade entre os valores empregados pelos municípios analisados. 
Tabela 4. Estatística descritiva dos valores das despesas empenhadas na função

\begin{tabular}{l|c|c|c|c}
\hline \multirow{2}{*}{} & $\mathbf{2 0 1 3}$ & $\mathbf{2 0 1 5}$ Despesas & $\mathbf{2 0 1 7}$ & $\mathbf{2 0 1 9}$ \\
\cline { 2 - 5 } & $\mathbf{R \$}$ & $\mathbf{R \$}$ & $\mathbf{R \$}$ & $\mathbf{R \$}$ \\
\hline Média & $6.948 .495,33$ & $8.354 .749,65$ & $9.365 .097,32$ & $10.176 .007,15$ \\
\hline Máximo & $36.098 .823,92$ & $47.004 .537,07$ & $49.898 .610,26$ & $46.486 .027,61$ \\
\hline Mínimo & $1.693 .829,60$ & $2.139 .218,43$ & $258.114,29$ & $1.951 .293,65$ \\
\hline Desvio Padrão & 6928085,0 & 8611101,8 & 9592500,8 & 9985567,6 \\
\hline
\end{tabular}

Fonte: Elaborado pelas autoras com dados coletados no Siconfi (2020).

Quanto aos dados referentes aos recursos físicos/materiais pode-se observar que aproximadamente $50 \%$ dos quarenta e dois (42) municípios analisados não sofreu alterações na quantidade de escolas nos anos analisados. Conforme a Tabela 5, destacaram-se os municípios de Ampére com o aumento de duas instituições, Nova Prata do Iguaçu com a diminuição de duas, e Salto do Lontra com a diminuição de três escolas.

Tabela 5. Quantidade de escolas municipais

\begin{tabular}{l|c|c|c|c}
\multicolumn{1}{c}{ Municípios } & \multicolumn{4}{c}{ Período } \\
\cline { 2 - 5 } & $\mathbf{2 0 1 3}$ & $\mathbf{2 0 1 5}$ & $\mathbf{2 0 1 7}$ & $\mathbf{2 0 1 9}$ \\
\hline Ampére & 6 & 6 & 8 & 8 \\
\hline Nova Prata do Iguaçu & 5 & 4 & 4 & 3 \\
\hline Salto do Lontra & 10 & 9 & 8 & 7 \\
\hline
\end{tabular}

Fonte: Elaborado pelas autoras com dados coletados no IBGE e INEP (2020).

Ao observar a média, média, máximo, mínimo e desvio padrão das escolas analisadas, pode-se observar, conforme demonstra a Tabela 6 , que durante os quatro períodos os resultados foram parecidos, demonstrando assim que a variação na quantidade de escolas durante esse período foi pequena.

Tabela 6. Estatística descritiva do número de escolas

\begin{tabular}{l|c|c|c|c}
\hline \multicolumn{5}{|c|}{ Escolas } \\
\hline Média & $\mathbf{2 0 1 3}$ & $\mathbf{2 0 1 5}$ & $\mathbf{2 0 1 7}$ & $\mathbf{2 0 1 9}$ \\
\hline Máximo & 6 & 6 & 6 & 6 \\
\hline Mínimo & 26 & 25 & 26 & 26 \\
\hline Desvio Padrão & 1 & 1 & 1 & 1 \\
\hline
\end{tabular}

Fonte: Elaborado pelas autoras com dados coletados no IBGE e INEP (2020).

A Tabela 7 traz as quantidades de matrículas e docentes apresentados nos anos iniciais do ensino fundamental, onde se destacaram os municípios de Francisco Beltrão, Pato Branco e Palmas com as maiores quantidades de recursos humanos utilizados na função, enquanto que apresentando as menores quantidades de alunos e professores estão Manfrinópolis, Sulina e Boa Esperança do Iguaçu.

Tabela 7. Quantidade de recursos humanos

\begin{tabular}{l|c|c|c|c|c|c|c|c}
\hline \multirow{2}{*}{\multicolumn{1}{c|}{ Municípios }} & \multicolumn{4}{|c|}{ Matrículas } & \multicolumn{4}{c}{ Docentes } \\
\cline { 2 - 10 } & $\mathbf{2 0 1 3}$ & $\mathbf{2 0 1 5}$ & $\mathbf{2 0 1 7}$ & $\mathbf{2 0 1 9}$ & $\mathbf{2 0 1 3}$ & $\mathbf{2 0 1 5}$ & $\mathbf{2 0 1 7}$ & $\mathbf{2 0 1 9}$ \\
\hline Francisco Beltrão & 5360 & 5285 & 5029 & 5265 & 298 & 268 & 303 & 369 \\
\hline Pato Branco & 4242 & 4246 & 4477 & 4479 & 219 & 207 & 209 & 221 \\
\hline Palmas & 4260 & 3907 & 4004 & 3633 & 190 & 181 & 176 & 163 \\
\hline Manfrinópolis & 235 & 216 & 185 & 181 & 27 & 22 & 19 & 19 \\
\hline
\end{tabular}




\begin{tabular}{l|l|l|l|l|l|l|l|l}
\hline Sulina & 246 & 193 & 180 & 179 & 13 & 11 & 12 & 14 \\
\hline Boa Esperança do Iguaçu & 215 & 168 & 170 & 152 & 15 & 15 & 15 & 14 \\
\hline
\end{tabular}

Fonte: Elaborado pelas autoras com dados coletados no IBGE e INEP (2020).

Quanto aos demais municípios da amostra, identificou-se que aproximadamente $81 \%$ dos municípios durante os anos investigados apresentaram queda na quantidade de alunos atendidos, ao passo que $19 \%$ da amostra analisada apresentou aumento no número de matrículas. Conforme observa-se na Tabela 8 , onde a média dos quatro períodos analisados apresentou queda, assim como as demais estatísticas.

Tabela 8. Estatística descritiva do número de matrículas

\begin{tabular}{l|c|c|c|c}
\hline \multicolumn{5}{|c}{ Matrículas } \\
\hline Média & $\mathbf{2 0 1 3}$ & $\mathbf{2 0 1 5}$ & $\mathbf{2 0 1 7}$ & $\mathbf{2 0 1 9}$ \\
\hline Máximo & 1015 & 966 & 926 & 889 \\
\hline Mínimo & 5360 & 5285 & 5029 & 5265 \\
\hline Desvio Padrão & 215 & 168 & 170 & 152 \\
\hline
\end{tabular}

Fonte: Elaborado pelas autoras com dados coletados no IBGE e INEP (2020).

Referente à variação no número de docentes, verificou-se que no último em comparação com o primeiro ano analisado, aproximadamente $55 \%$ dos municípios investigados apresentaram redução no quadro de profissionais, enquanto que $43 \%$ aumentaram a quantidade, fato que ocasionou que a média de docentes dos quatro períodos permanecesse com valores aproximados. Contudo pode-se observar, conforme a Tabela 9, que a quantidade máxima de docentes teve aumento, mínima quase não teve alteração, enquanto que o desvio padrão entre as quantidades sofreu aumento.

Tabela 9. Estatística descritiva do número de docentes

\begin{tabular}{l|c|c|c|c}
\hline \multicolumn{5}{|c}{ Docentes } \\
\hline Média & $\mathbf{2 0 1 3}$ & $\mathbf{2 0 1 5}$ & $\mathbf{2 0 1 7}$ & $\mathbf{2 0 1 9}$ \\
\hline Máximo & 58 & 57 & 57 & 58 \\
\hline Mínimo & 298 & 268 & 303 & 369 \\
\hline Desvio Padrão & 13 & 11 & 12 & 12 \\
\hline
\end{tabular}

Fonte: Elaborado pelas autoras com dados coletados no IBGE e INEP (2020).

Diante da quantidade de alunos e docentes levantadas, buscou-se analisar a relação aluno/docente, conforme mostra a Tabela 10. Onde pode-se observar que Coronel Domingos Soares apresentou no ano de 2013 a maior relação do período. Contudo, nos próximos períodos analisados sofreu queda nos números apresentados.

Tabela 10. Relação aluno/docente

\begin{tabular}{l|c|c|c|c}
\hline \multirow{2}{*}{ Municípios } & \multicolumn{3}{c}{ Período } \\
\cline { 2 - 5 } & $\mathbf{2 0 1 3}$ & $\mathbf{2 0 1 5}$ & $\mathbf{2 0 1 7}$ & $\mathbf{2 0 1 9}$ \\
\hline Palmas & 22 & 22 & 23 & 22 \\
\hline Salto do Lontra & 18 & 25 & 23 & 18 \\
\hline Pato Branco & 19 & 21 & 21 & 20 \\
\hline Coronel Domingos Soares & 26 & 13 & 14 & 12 \\
\hline Realeza & 12 & 12 & 11 & 10 \\
\hline São João & 11 & 10 & 9 & 10 \\
\hline Manfrinópolis & 9 & 10 & 10 & 10 \\
\hline
\end{tabular}

Fonte: Elaborado pelas autoras com dados coletados no IBGE e INEP (2020). 
Por meio da Tabela 10 pode-se observar ainda, que os municípios de Realeza, São João e Manfrinópolis classificaram-se como os que apresentaram as menores quantidades de alunos por docentes disponíveis. Identificou-se ainda os municípios de Palmas, Salto do Lontra e Pato Branco, que apresentaram nos períodos analisados as maiores relações aluno/docente dentre os municípios investigados.

Quanto às notas obtidas pelos municípios nas avaliações do IDEB, por meio da Tabela 11, verificou-se que Bom Sucesso do Sul e Pato Branco nas quatro avaliações alcançaram bons resultados, enquanto que Bela Vista da Caroba e Palmas apresentaram baixos índices, com notas inferiores a seis (6) em todas as avaliações.

Tabela 11. Notas dos municípios no IDEB

\begin{tabular}{l|c|c|c|c|c|c|c|c}
\hline \multirow{2}{*}{ Municípios } & \multicolumn{2}{c|}{$\mathbf{2 0 1 3}$} & \multicolumn{2}{c|}{ 2015 } & \multicolumn{2}{c|}{ 2017 } & \multicolumn{2}{c}{ 2019 } \\
\cline { 2 - 10 } & IDEB & Meta & IDEB & Meta & IDEB & Meta & IDEB & Meta \\
\hline Bom Sucesso do Sul & 7.5 & 5.5 & 7.2 & 5.8 & 7.7 & 6.0 & 8.0 & 6.3 \\
\hline Bela Vista da Caroba & 4.8 & 4.6 & 5.7 & 4.9 & 5.6 & 5.2 & 5.9 & 5.4 \\
\hline Palmas & 4.7 & 4.4 & 4.8 & 4.7 & 5.0 & 5.0 & 5.1 & 5.3 \\
\hline Pato Branco & 6.3 & 5.6 & 7.1 & 5.9 & 7.5 & 6.1 & 7.3 & 6.4 \\
\hline
\end{tabular}

Fonte: Elaborado pelas autoras com dados do IDEB e INEP (2020).

Observou-se ainda que quanto às metas projetadas individualmente para cada município, no ano de 2013 três (3), ou 7\%, no período de 2015 dois (2) ou 5\% da amostra não alcançaram a meta. Posteriormente, na avaliação de 2017 oito (8) ou 19\% dos municípios não alcançaram a meta estimada, e na avaliação mais recente de 2019 o número de municípios diminuiu para quatro (4) ou $10 \%$ do total de municípios.

Utilizando como parâmetro para análise da qualidade da educação básica a média geral seis (6) estipulada pelo MEC, pode-se observar que no ano de 2013 aproximadamente $56 \%$ da amostra analisada atingiu ou ultrapassou a média seis (6) em contrapartida de $44 \%$ de municípios que ficaram com índices abaixo da média. No ano de 2015 e 2017 observou-se o aumento nesse percentual, onde $71 \%$ e $74 \%$, respectivamente nos dois anos, atingiram ou ultrapassaram a média seis (6) em contrapartida de $29 \%$ em 2015 e $26 \%$ em 2017 dos municípios que ficaram com índices abaixo da média. Por fim, apresentaram-se no ano de 2019 aproximadamente $88 \%$ dos municípios índices superiores a seis (6), demonstrando assim o aumento na qualidade de ensino promovida pelos municípios aos primeiros anos do ensino fundamental no decorrer dos quatro anos analisados.

Dado que é possível identificar também por meio da média, máximo e mínimo, os quais no decorrer dos anos analisados apresentou aumento, enquanto que o desvio padrão sofreu queda, demonstrando que a diferença de notas entre os municípios diminuiu.

Tabela 12. Estatística descritiva das notas do IDEB

\begin{tabular}{l|c|c|c|c}
\hline \multicolumn{5}{c}{ Notas do IDEB } \\
\hline Média & $\mathbf{2 0 1 3}$ & $\mathbf{2 0 1 5}$ & $\mathbf{2 0 1 7}$ & $\mathbf{2 0 1 9}$ \\
\hline Máximo & 6,0 & 6,3 & 6,4 & 6,6 \\
\hline Mínimo & 7,5 & 7,2 & 7,7 & 8,0 \\
\hline Desvio Padrão & 4,6 & 4,8 & 5,0 & 5,1 \\
\hline
\end{tabular}

Fonte: Elaborado pelas autoras com dados do IDEB e INEP (2020). 


\subsection{Análise da Eficiência}

Com uso da ferramenta DEA foi mensurada a eficiência na utilização dos recursos públicos nos anos iniciais do ensino fundamental dos municípios da amostra, nos anos de 2013, 2015, 2017 e 2019. Os resultados obtidos estão demonstrados na Tabela 13, onde foram dispostos em ordem decrescente de valores, ou seja, das maiores para as menores eficiências.

Tabela 13. Grau de eficiência na utilização dos recursos pelos municípios

\begin{tabular}{|c|c|c|c|c|}
\hline \multirow{2}{*}{ Municípios } & \multicolumn{4}{|c|}{ Período } \\
\hline & 2013 & 2015 & 2017 & 2019 \\
\hline Boa Esperança do Iguaçu & 1,000 & 1,000 & 1,000 & $\mathbf{1 , 0 0 0}$ \\
\hline Bom Sucesso do Sul & 1,000 & 1,000 & 1,000 & $\mathbf{1 , 0 0 0}$ \\
\hline Sulina & 1,000 & 1,000 & 1,000 & 0,975 \\
\hline Pato Branco & 0,840 & 0,986 & 1,000 & $\mathbf{1 , 0 0 0}$ \\
\hline Pinhal de São Bento & 1,000 & - & 0,884 & $\mathbf{1 , 0 0 0}$ \\
\hline Realeza & 0,920 & 0,958 & 0,978 & 0,939 \\
\hline São João & 0,920 & 0,958 & 0,950 & 0,920 \\
\hline Vitorino & 0,872 & 0,986 & 0,975 & 0,864 \\
\hline Santa Izabel do Oeste & 0,827 & 0,972 & 0,963 & 0,907 \\
\hline Itapejara D' Oeste & 0,880 & 0,917 & 0,937 & 0,921 \\
\hline Salgado Filho & 0,853 & 0,958 & 0,886 & 0,921 \\
\hline Enéas Marques & 0,880 & 0,889 & 0,910 & 0,939 \\
\hline Planalto & 0,907 & 0,972 & 0,833 & 0,883 \\
\hline Dois Vizinhos & 0,853 & 0,917 & 0,892 & 0,900 \\
\hline Bom Jesus do Sul & 0,924 & 0,819 & 0,983 & 0,834 \\
\hline Francisco Beltrão & 0,813 & 0,875 & 0,847 & $\mathbf{1 , 0 0 0}$ \\
\hline São Jorge D' Oeste & 0,827 & 0,931 & 0,872 & 0,875 \\
\hline Marmeleiro & 0,813 & 0,917 & 0,911 & 0,859 \\
\hline Saudade do Iguaçu & 0,771 & 0,861 & 1,000 & 0,838 \\
\hline Renascença & 0,771 & 0,889 & 0,915 & 0,854 \\
\hline Nova Esperança do Sudoeste & - & 0,931 & 0,831 & 0,813 \\
\hline Flor da Serra do Sul & 0,840 & 0,889 & 0,805 & 0,888 \\
\hline Salto do Lontra & 0,813 & 0,889 & 0,885 & 0,820 \\
\hline Capanema & 0,787 & 0,903 & 0,861 & 0,852 \\
\hline Ampére & 0,827 & 0,847 & 0,875 & 0,854 \\
\hline Manfrinópolis & 0,747 & 0,861 & 0,868 & 0,911 \\
\hline Verê & 0,813 & 0,903 & 0,807 & 0,866 \\
\hline Cruzeiro do Iguaçu & 0,867 & 0,819 & 0,819 & 0,826 \\
\hline Pérola D' Oeste & 0,840 & 0,847 & 0,832 & 0,789 \\
\hline Chopinzinho & 0,813 & 0,875 & 0,797 & 0,815 \\
\hline Bela Vista da Caroba & 0,696 & 0,792 & 0,767 & $\mathbf{1 , 0 0 0}$ \\
\hline Coronel Vivida & 0,773 & 0,833 & 0,796 & 0,841 \\
\hline Nova Prata do Iguaçu & 0,760 & 0,819 & 0,754 & 0,790 \\
\hline Santo Antônio do Sudoeste & 0,747 & 0,847 & 0,784 & 0,802 \\
\hline Mariópolis & 0,733 & 0,819 & 0,754 & 0,814 \\
\hline Mangueirinha & 0,747 & 0,792 & 0,717 & 0,787 \\
\hline Pranchita & 0,707 & 0,806 & 0,793 & 0,726 \\
\hline Barracão & 0,747 & 0,792 & 0,690 & 0,792 \\
\hline Honório Serpa & 0,733 & 0,806 & 0,689 & 0,750 \\
\hline Clevelândia & 0,720 & 0,792 & 0,744 & 0,712 \\
\hline Palmas & 0,627 & 0,667 & 1,000 & 0,670 \\
\hline Coronel Domingos Soares & 0,613 & 0,667 & 0,677 & 0,680 \\
\hline
\end{tabular}

Fonte: Dados da Pesquisa (2020)

Por meio da Tabela 13, pode-se observar que os municípios que alcançaram o grau 
máximo de eficiência $(1,000)$, durante os quatro anos analisados, foram Boa Esperança do Iguaçu e Bom Sucesso do Sul, seguidos pelo município de Sulina, que nos três primeiros anos alcançou a eficiência. Contudo, no último ano investigado não alcançou o grau 1,000. Ademais, também alcançaram a pontuação máxima na análise, no ano de 2013: Pinhal de São Bento; no ano de 2017: Pato Branco, Saudade do Iguaçu e Palmas, e no ano de 2019: Pato Branco, Pinhal de São Bento, Francisco Beltrão e Bela Vista da Caroba, os quais serviram de benchmarking para os demais municípios da amostra, respectivamente aos períodos que alcançaram o nível máximo de eficiência.

Destacaram-se com os menores graus de eficiência, conforme mostra a Tabela 13, os municípios de Coronel Domingos Soares e Palmas, que apesar de ter alcançado a eficiência no ano de 2017, nos outros períodos alcançou baixos índices.

Verificou-se que, Boa Esperança do Iguaçu, Bom Sucesso do Sul e Sulina, que apesar de se apresentarem como os municípios com quantidades menores de recursos empregados na função, em relação aos demais municípios da amostra, obtiveram bons resultados nas avaliações do IDEB. Por meio da análise atingiram a eficiência na utilização dos recursos disponíveis. Enquanto que Palmas, identificado por meio da análise descritiva como um dos municípios que mais destinava recursos públicos para educação, alcançou baixos índices, demonstrando que esses recursos não estão sendo bem alocados.

Diante dos resultados obtidos por meio da DEA, evidenciados na Tabela 13, foram classificados os níveis de eficiência de acordo com os índices obtidos, onde se agrupou como eficientes aqueles municípios que atingiram o grau 1,000; com ineficiência fraca aqueles com resultados $0,800 \leq \mathrm{a}<1,000$; ineficiência moderada os que apresentaram índices $0,600 \leq \mathrm{a}<$ 0,800 , e os que tiveram um grau a $<0,600$ com ineficiência forte, conforme demonstra a Tabela 14.

Tabela 14. Classificação da eficiência

\begin{tabular}{|c|c|c|c|c|}
\hline \multirow{2}{*}{ Nível de Eficiência } & \multicolumn{4}{|c|}{ Período } \\
\hline & 2013 & 2015 & 2017 & 2019 \\
\hline Eficientes $(\mathbf{a}=\mathbf{1 , 0 0 0})$ & $4(10 \%)$ & $3(7 \%)$ & $6(14 \%)$ & $6(14 \%)$ \\
\hline Ineficiência Fraca $(0,800 \leq a<1,000)$ & $21(51 \%)$ & $32(78 \%)$ & $24(57 \%)$ & $27(64 \%)$ \\
\hline Ineficiência Moderada $(0,600 \leq \mathbf{a}<\mathbf{0 , 8 0 0 )}$ & $16(39 \%)$ & $6(15 \%)$ & $12(29 \%)$ & $9(22 \%)$ \\
\hline Ineficiência Forte $(\mathbf{a}<0,600)$ & 0 & 0 & 0 & 0 \\
\hline
\end{tabular}

Fonte: Dados da Pesquisa (2020).

Por meio da Tabela 14 se pode observar que a quantidade de municípios que alcançaram o grau máximo 1,000, sendo assim classificados como eficientes foram quatro (4) em 2013; três (3) em 2015; seis (6) em 2017; e, seis (6) em 2019, representando 10\%, 7\%, 14\% e 14\% dos municípios analisados respectivamente durante os quatro períodos analisados.

De acordo com os resultados demonstrados na Tabela 14, as porcentagens de municípios da amostra consideradas eficientes foram próximas às encontrados por Amaral et al. (2019) em sua pesquisa, superiores aos achados de Besen et al. (2017), Monte e Leopoldino (2017) e Savian e Bezerra (2013) em suas respectivas pesquisas, e divergentes dos achados de Mattei e Bezerra (2018), onde o percentual eficiente encontrado foram maiores que os achados da presente pesquisa. Em relação à Rech et al. (2014) e Bohrer et al. (2013), que apresentam em suas pesquisas, a mesma amostra de municípios analisados no presente trabalho, os resultados foram superiores.

Verificou-se que a grande maioria dos municípios analisados pela presente pesquisa representando 51\% em 2013; 78\% em 2015; 57\% em 2017; e, 64\% em 2019, apresentaram índices que variam de 0,800 até 0,999, os quais, apesar de serem considerados como uma ineficiência fraca, apresentam possibilidades de melhorias para alcançar assim a eficiência. 
O grande percentual de municípios encontrado pela pesquisa que apresentam graus que variam de 0,800 a 0,999, contribuem com os achados de Mattei e Bezerra (2018), onde a maioria dos municípios nos dois anos analisados em sua pesquisa apresentou ineficiência com escores que variam de 0,850 a 0,999. Divergem dos achados de Monte e Leopoldino (2017) e Savian e Bezerra (2013) onde a maior parte da amostra analisada possui ineficiência considerada moderada com graus que variam de 0,600 até 0,799 .

Divergem ainda dos achados de Besen et al. (2017), onde aproximadamente $62 \%$ dos estados analisados apresentam índices inferiores a 0,600, os quais na pesquisa dos autores são classificados com "Bom" e "Médio" grau de eficiência. Os resultados da presente pesquisa contrariam também os achados de Rech et al. (2014) e Bohrer et al. (2013), onde a grande maioria dos municípios apresenta índices inferiores a 0,600, ou que variam de 0,600 a 0,799.

A presente pesquisa identificou ainda que $39 \%$ em 2013; 15\% em 2015; $29 \%$ em 2017; e, $22 \%$ em 2019, dos municípios apresentam graus que variam de 0,600 até 0,799, sendo classificados com uma ineficiência considerada moderada. Verificou-se ainda que nenhum município teve uma ineficiência forte, com grau inferior a 0,600. Ao contrário de todos os estudos anteriores que apresentaram dentre seus resultados municípios com grau menor que 0,600 .

Ao comparar os quatro períodos investigados na presente pesquisa, verificou-se que de 2013 para 2015 ocorreu queda na quantidade de municípios classificados com eficiência e ineficiência moderada e o aumento de municípios com ineficiência fraca. De 2015 para 2017 pode-se observar que a quantidade de municípios com ineficiência fraca diminuiu, enquanto que os classificados com ineficiência moderada e eficiência aumentaram. Por fim, de 2017 para 2019 observou-se que a quantidade de municípios eficientes continuou a mesma, enquanto que a ineficiência fraca teve aumento e a ineficiência moderada apresentou queda.

Com isso, pode-se observar que a quantidade de municípios que atingiram a eficiência máxima durante os anos analisados sofreu uma queda, posteriormente um aumento e por fim, se manteve na mesma proporção. Verificou-se que a grande maioria dos municípios analisados apresenta grau de eficiência que varia de 0,800 a 0,999 , sendo classificados com ineficiência fraca. Identificou-se por fim que a quantidade de municípios que atingiu a eficiência na utilização dos recursos públicos nos quatro anos analisados é menor que $15 \%$ de total de municípios pertencentes à região Sudoeste do Paraná, demonstrando que os gestores não estão alocando os recursos de maneira eficiente, indicando assim, possibilidades para melhorias e a necessidade da revisão de práticas de planejamento para o melhor aproveitamento dos recursos disponíveis.

\section{CONSIDERAÇÕES FINAIS}

A presente pesquisa teve como objetivo analisar a eficiência dos recursos públicos destinados aos anos iniciais do ensino fundamental nas escolas públicas de responsabilidade dos municípios do Sudoeste do Paraná durante os anos de 2013, 2015, 2017 e 2019 utilizando a metodologia DEA com o modelo BCC e orientação a output.

Por meio do levantamento dos recursos financeiros, destinados às escolas públicas em cada um dos municípios da amostra, destacaram-se Pato Branco, Francisco Beltrão e Palmas, sendo estes os municípios mais populosos da região, foram os que destinaram os maiores montantes de recursos, para a função ensino fundamental. Enquanto que os municípios que se destacaram com os menores montantes investidos nos períodos analisados foram Boa Esperança do Iguaçu, Bela Vista da Caroba e Sulina. Nos quatro anos analisados, os gastos por alunos de todos os municípios apresentaram valores próximos a média dos demais municípios analisados.

Quantos aos recursos físicos/materiais destacou-se que 50\% dos municípios analisados 
não sofreram alteração na quantidade de escolas durante os períodos investigados. Em relação aos recursos humanos, pode-se destacar que a grande maioria dos municípios no decorrer dos anos sofreu redução na quantidade de alunos atendidos, enquanto que a quantidade de docentes empregados para função diminuiu em metade dos municípios analisados.

Quanto às notas alcançadas no IDEB se destacou o aumento na qualidade da educação na maioria dos municípios, onde de $56 \%$ de municípios no primeiro período analisado pela pesquisa ocorreu o aumento para $88 \%$ que obtiveram ou ultrapassaram a nota seis (6) na última avaliação analisada.

Os resultados da eficiência, mensurados pela DEA, indicam que a quantidade de municípios eficientes é considerada baixa durante os anos de 2013, quatro (4); 2015, três (3); 2017 seis (6); e 2019, seis (6) municípios da amostra analisada. Demonstrando-se assim necessária revisão das práticas de gestão, assim como ação efetiva do poder executivo quanto aos métodos adotados a fim de alcançar melhor aproveitamento dos recursos públicos, gerando alocações eficientes.

Destacou-se ainda, que mais da metade do total de quarenta e dois (42) municípios analisados apresenta ineficiência fraca com índices que variam de 0,800 a 0,999 , representando: vinte e um (21) em 2013; trinta e dois (32), em 2015; vinte e quatro (24) em 2017; e, vinte e sete (27) dos municípios em 2019. Conclui-se que apesar da folga para melhoria ser considerada pequena, os resultados indicam que é preciso identificar os gargalos e melhorar o planejamento, a fim de melhorar a produtividade desses municípios.

Constatou-se ainda que, a quantidade de recursos empregados não está diretamente relacionada com a eficiência, uma vez que atingiram a eficiência municípios com menores quantidades de recursos alocados como Boa Esperança do Sudoeste, Bom Sucesso do Sul e Sulina, assim como os que mais destinaram recursos como Pato Branco e Francisco Beltrão. Contudo, se observou, nos períodos, tendência de mais municípios com menores alocações atingirem a eficiência.

Por se tratar de um tema fundamental para o desenvolvimento social e econômico, para pesquisas futuras sugere-se que sejam feitas análises da eficiência em cada município individualmente, assim como a análise qualitativa da educação nos municípios do Sudoeste do Paraná, a fim de identificar quais são os fatores que influenciam para o alcance da eficiência ou deixam a desejar espaços de melhoria. Sugere-se também que sejam realizadas avaliações de eficiência não somente na educação básica, mas também nos anos finais do ensino fundamental, assim como, no ensino médio e superior.

\section{REFERÊNCIAS}

Amaral, J. T., Santos, G. C., \& Santos, D. C. (2019). A eficiência na gestão dos gastos públicos com educação fundamental no Estado do Rio de Janeiro: um estudo baseado na análise envoltória de dados. Pensar Contábil, 21(76), 28-38.

Amorim, K. A. F., Diniz, J. A., Lima, S. C., \& Amorim, A. Z. F. (2016, julho). Eficiência dos gastos públicos com educação fundamental dos municípios paraibanos em função dos pareceres de julgamento de contas emitidos pelo Tribunal de Contas do Estado da Paraíba. Anais do Congresso USP de Iniciação Científica em Contabilidade, São Paulo, SP, Brasil, 13.

Besen, F.G., Scherer, G., Araújo, T. V., \& Serafim Jr., V. S. (2017, julho). Eficiência dos gastos no ensino médio do ano de 2013 nos estados brasileiros a partir da análise envoltória de 
dados (DEA). Anais do Congresso USP de Iniciação Científica em Contabilidade, São Paulo, SP, Brasil, 14.

Bohrer, É., Comunelo, A. L., \& Godarth, K. A. L. (2013). Eficiência do gasto público na educação: o caso do Sudoeste do Paraná, Brasil. CAP Accounting and Management, 1(7), 209-222. Recuperado em 8 julho, 2020, de ttp://revistas.utfpr.edu.br/pb/index.php/CAP/article/view/1705/1169

Boueri, R., Rocha, F., \& Rodopoulos, F. (2015). Avaliação da qualidade do gasto público e mensuração da eficiência. Secretaria do Tesouro Nacional. Brasília.

Constituição da República Federativa do Brasil de 1988 (2016). Recuperado em 14 outubro, 2019, de www.planalto.gov.br/ccivil_03/constituicao/constituicao.htm

Couto, L. C., Barbosa Neto, J. E., \& Resende, L. L. (2018, janeiro/abril). Flexibilidade do orçamento público perante a execução orçamentária. RMC - Revista Mineira de Contabilidade, 19(1), 42-54.

Instituto Paranaense de Desenvolvimento Econômico e Social. (2020). Perfil avançado das regiões geográficas. Recuperado em 16 março, 2020, de www.ipardes.pr.gov.br/.

Kohama, H. (2017). Contabilidade Pública: teoria e prática (15a ed.) São Paulo: Atlas.

Lourenço, R. L., Angotti, M., Nascimento, J. C. H. B., \& Sauerbronn, F. F. (2017, janeiro/abril). Eficiência do gasto público com ensino fundamental: uma análise dos 250 maiores municípios brasileiros. Revista Contabilidade Vista e Revista, 28(1).

Mattei, T. S., \& Bezerra, F. M. (2018, julho/dezembro). Eficiência dos gastos públicos com educação: evidências para o ensino fundamental de Santa Catarina. Revista eletrônica de Programa de Mestrado em Desenvolvimento Regional da Universidade do Contestado, 8(2), 27-46. Recuperado em 8 agosto, 2020, de www.periodicos.unc.br/index.php/drd/article/view/1486

Meza, L.Â., Biondi Neto, L., Mello, J. C. C. B. S., \& Gomes, E. G. (2015, dezembro). ISYDS - Sistema Integrado de Apoio à Decisão (SIAD - Sistema Integrado de Apoio à Decisão): um pacote de software para modelo de análise envoltória de dados. Pesqui. Oper., 25(3), 493-503. Recuperado em 7 outubro, 2020, de www.scielo.br/scielo.php?script=sci_arttext\&pid=S0101$74382005000300011 \& \operatorname{lng}=$ en\&nrm=iso.

Monte, M. M., \& Leopoldino, C. B. (2017, julho/setembro). Eficiência dos gastos municipais em educação no Ceará. Revista Pensamento Contemporâneo em Administração, 11(4), 4455.

Nova, S. P. C. C., \& Santos, A. (2008, maio/agosto). Aplicação da análise por envoltória de dados utilizando variáveis contábeis. Revista de Contabilidade e Organizações, 3(2), 132 -154 .

Oliveira, A. F. (2010). Políticas públicas educacionais: conceito e contextualização numa 
perspectiva didática. Fronteiras da Educação: desigualdades, tecnologias e políticas, 9399. Recuperado em 13 outubro, 2020, de www.aedmoodle.ufpa.br/pluginfile.php/169363/mod_resource/content/2/OLIVEIRAPol\%C3\%83-ticas\%20p\%C3\%83\%C2\%BAblicas\%20educacionais....pdf.

Oliveira, C. L., \& Ferreira, F. G. B. C. (2017, agosto). O Orçamento público no estado constitucional democrático e a deficiência crônica na gestão das finanças públicas no Brasil. Sequência, (76), 183-212. Recuperado em 13 outubro, 2020, de www.scielo.br/scielo.php?pid=S2177$70552017000200183 \&$ script=sci_abstract\&tlng=pt.

Paz, F. M., \& Raphae, H. S. (2012, julho/dezembro). Contribuição para o debate sobre a escola pública: O Índice de Desenvolvimento da Educação Básica. Colloquium Humanarum, 9(2), $55-65$.

Peña, C. R. (2008, janeiro/março). Um modelo de avaliação da eficiência da administração pública através do método análise envoltória de dados (DEA). Revista de Administração Contemporânea, 12(1), 83-106.

Procópio, J. (2020, outubro 21). Região - 21 municípios do Sudoeste ultrapassam índices permitidos para pagamentos de servidores. Diário Do Sudoeste. Recuperado em 22 novembro, 2020, de https://diariodosudoeste.com.br/regiao/21-municipios-do-sudoesteultrapassam-indices-permitidos-para-pagamentos-de-servidores/.

Rech, A. T., Comunelo, A. L., \& Godarth, A. L. (2014). Análise da eficiência dos gastos públicos na educação fundamental dos municípios do Sudoeste do Estado do Paraná. Anais do Encontro da ANPAD. Rio de Janeiro, RJ, Brasil, 38.

Santos, L. A., \& Camacho, E. U. (2014, maio/agosto). Orçamento público municipal: uma análise no município de Cosmópolis/SP com enfoque no equilíbrio das receitas $\mathrm{x}$ despesas no período de 2007 a 2012. Revista Evidenciação Contábil \& Finanças, 2(2), 82-94.

Savian, M. P. G., \& Bezerra, F. M. (2013, janeiro/julho). Análise de eficiência dos gastos públicos com educação no ensino fundamental no Estado do Paraná. Economia \& Região, $1(1), 26-47$.

Silva, A. A. P., Ferreira, M. A. M., Braga, M. J., \& Abrantes, L. A. (2012, janeiro/abril). Eficiência na alocação de recursos públicos destinados à educação, saúde e habitação em municípios mineiros. Contabilidade, Gestão e Governança, 15(1), 96-114.

Silva, J. L. M., \& Almeida, J. C. L. (2012, julho/dezembro). Eficiência no gasto público com educação: uma análise dos municípios do Rio Grande do Norte. Planejamento e Políticas Públicas, (39), 219-242.

Silva, M. C., Souza, F. J. V., Silva, J. D. G., \& Borges, E. F. (2016). Índice de desenvolvimento da educação básica dos Estados e do Distrito Federal: avaliação em um único índice 20052013. Revista Capital Científico - Eletrônica (RCCe). Recuperado em 13 outubro, 2019, de revistas.unicentro.br/index.php/capitalcientifico/article/view/3483. 
Souza, F. J. V., Silva, M. C., \& Araujo, A.O. (2012). Análise da eficiência dos gastos públicos em educação dos municípios do Estado do Estado do Rio Grande do Norte nos anos de 2007 e 2009. Anais do Congresso USP de Iniciação Científica em Contabilidade. São Paulo, SP, Brasil, 9.

Souza, P. C. T., \& Wilhelm, V. E. (2009). Uma introdução aos modelos DEA de eficiência técnica. Tuiuti: Ciência e Cultura, (42), 141-150.

Telles, T. S., Suguihiro, V. L. T., \& Barros, M. N. F. (2011). Os direitos de crianças e adolescentes na perspectiva orçamentária. Serviço Social e Sociedade, (105), 50-66. 